\title{
GCU
}

Glasgow Caledonian

University

University for the Common Good

\section{Vehicular Safety Application Identifier algorithm for LTE VANET server}

Ansari, Shuja Shahid; Boutaleb, Tuleen; Gamio, Carlos; Sinanovic, Sinan; Krikidis, loannis; Sánchez, Marvin

Published in:

8th International Congress on Ultra Modern Telecommunications and Control Systems and Workshops (ICUMT)

DOI:

10.1109/ICUMT.2016.7765229

Publication date:

2016

Document Version

Author accepted manuscript

Link to publication in ResearchOnline

Citation for published version (Harvard):

Ansari, SS, Boutaleb, T, Gamio, C, Sinanovic, S, Krikidis, I \& Sánchez, M 2016, Vehicular Safety Application Identifier algorithm for LTE VANET server. in 8th International Congress on Ultra Modern Telecommunications and Control Systems and Workshops (ICUMT). IEEE, pp. 37-42. https://doi.org/10.1109/ICUMT.2016.7765229

\section{General rights}

Copyright and moral rights for the publications made accessible in the public portal are retained by the authors and/or other copyright owners and it is a condition of accessing publications that users recognise and abide by the legal requirements associated with these rights.

Take down policy

If you believe that this document breaches copyright please view our takedown policy at https://edshare.gcu.ac.uk/id/eprint/5179 for details of how to contact us. 


\title{
Vehicular Safety Application Identifier Algorithm for LTE VANET Server
}

\author{
Shuja Ansari ${ }^{1}$, Tuleen Boutaleb ${ }^{1}$, Carlos Gamio ${ }^{1}$, Sinan Sinanovic ${ }^{1}$, Ioannis Krikidis ${ }^{2}$ and Marvin Sánchez ${ }^{3}$ \\ ${ }^{1}$ School of Engineering and Built Environment, Glasgow Caledonian University, Glasgow, Scotland UK \\ Email: Shuja.Ansari, T.Boutaleb, Carlos.Gamio, Sinan.Sinanovic@gcu.ac.uk \\ ${ }^{2}$ Department of Electrical and Computer Engineering, Faculty of Engineering, University of Cyprus \\ Email: krikidis@ucy.ac.cy \\ ${ }^{3}$ Faculty of Electric, Electronic and Computer Science, National University of Engineering, Managua, Nicaragua \\ Email: marvin.sanchez@uni.edu.ni
}

\begin{abstract}
Vehicular communications have been an incentive for driver safety and ultimately autonomous smart vehicles. These vehicular networks have strict requirements with transmission frequency, range, and delay. From previous contributions, Long Term Evolution (LTE) has been found to meet the requirements for vehicular networks. Extensive realistic system level simulations, including multipath and multi cell environments, have been carried out to evaluate the performance of LTE networks for vehicular communications. This paper improves upon previously contributed simulations by introducing Safety Application Identifier along with an algorithm that implements differentiated Quality of Service (QoS) for different safety applications that are handled by the vehicular server located within the LTE core network. Results show that the probability of end-to-end delay below $100 \mathrm{~ms}$ increases by $20 \%$, downlink goodput of the system improves reducing the amount of vehicular application traffic, and eventually the number of downlink flows is reduced by $60 \%$; improving network capacity. Moreover, with the implementation of the proposed algorithm, high QoS can be achieved for vehicular safety applications in terms of delay and packet delivery.
\end{abstract}

\section{INTRODUCTION}

Intelligent transportation systems (ITS) requiring wireless communications have set forth a demand for a cooperative network with some stringent requirements. To support these requirements vehicular ad hoc networks (VANETs) have proved themselves to be promising. Vehicles equipped with sensors and communication devices form VANETs, which have attracted operators and service providers in provisioning driver safety, traffic efficiency and infotainment. Two forms of communications are classified in VANETs, vehicle to vehicle (V2V) and vehicle to infrastructure (V2I). IEEE Standard $802.11 \mathrm{p}$ has been formulated with some amendments in Wi-Fi standard to support these communications. However, in order to provide V2I communications, an entirely new infrastructure is required. Considering this economical issue, a number of studies have proposed the use of already installed cellular infrastructure [1], [2].

In terms of increasing traffic and demanding Quality of Service (QoS), cellular networks are ubiquitous. With the swift roll out of evolved universal mobile telecommunications service terrestrial radio access networks (E-UTRAN, commercially referred as Long Term Evolution (LTE)), network operators and service providers have achieved high data rates and lower latencies. Previous performance evaluations have suggested that the use of LTE for vehicular communications is suitable, but without any centralization, it can put enormous load on the network [3]. In the pursuit of centralizing vehicular communications on LTE, group formation and multicast/broadcast management system (MBMS) implementation have been proposed in [3] and [4]. Group formation or clustering has shown promising performance. However, clustering relies on relaying transmissions which can pose a privacy and security issue [5]. On the other hand, MBMS functionality, though being the part of 3GPP specifications, is not widely implemented by operators [6], [7].

VANET applications can be classified into three categories; safety application, transport efficiency and entertainment/information [8]. Transport efficiency includes traffic light optimal speed advisory, to assist the driver to drive by during the green phase, and safety application would include cooperative forward collision warning, to avoid rear-end collisions. The focus of this paper is on the safety applications.

Kato et al. [9] defined the concept of data freshness and the authors used this parameter to evaluate the performance of LTE networks with VANETs. If a vehicle application transmits a packet at a frequency of $10 \mathrm{~Hz}$, that is a message is transmitted every $100 \mathrm{~ms}$, the freshness requirement for that specific application would be $100 \mathrm{~ms}$. They observed that it is possible to achieve a freshness of $100 \mathrm{~ms}$ using LTE. Authors also evaluated the impact of vehicular application server's location in the LTE network. In this paper, we utilize the server to forward the safety messages to the vehicles.

Similarly, LTE performance with VANETs has been investigated in [10], [11] and [12], concluding that LTE has higher latencies than dedicated short range communications (DSRC). Nonetheless LTE demonstrates acceptable requirements in terms of latency and successful delivery for vehicular networks. In terms of the performance evaluations and system level simulations, researchers have simulated various transmission parameters (beacon frequency and transmission range) individually without employing urban vehicular fading models, lacking the authenticity of real world scenarios in their models [11], [12]. System level simulations carried out in this 
paper employ a multicell urban vehicular radio environment, including multipath fading models along with scenarios using different transmission parameters simultaneously unlike [11] and [12].

Moreover, when an user equipment (UE) engages in multiple applications, the LTE network in order to cater all the requirements, associates each application flow with a bearer. These bearers are set up within the evolved packet system (EPS), associated with a QoS in order to support their multiple requirements [13, Ch.2]. This stringent implementation of QoS in LTE networks makes the system robust and reliable. Similar concept of parameter association is introduced and implemented. Our paper also employs the concept of awareness range, previously elaborated in [14] and [15], as the geographical area around the vehicle where all the neighbors are to be made cognizant of the vehicle.

The previous works discussed along with the understanding of the gaps in terms of simulation models and the vitality of a differentiated QoS requirement motivate the work presented in this paper. Main contributions of this paper are summarized as followed:

- Safety Application Identifier (SAI) mechanism that categorizes the different vehicular applications based on their transmission requirements (beacon frequency and awareness range).

- SAI Algorithm implementation with system level simulations on the server located within Core Network (CN) ensuring efficient packet dissemination within the vehicular network in a multicell urban vehicular radio environment employing multipath fading channels.

Based on these contributions, we analyse the LTE system performance for VANETs utilizing SAI algorithm with the help of ns-3. The remainder of this paper is organized as follows: Section II describes the SAI concept, and Section III elaborates on the system model followed by simulation results in Section IV. Conclusions and future work are then discussed within Section V.

\section{SAfety ApPlication IDENTIFIER CONCEPT}

A survey was carried out to compile a set of vehicular safety applications. European standards include some of the important set of applications [16]. Moreover, from various sources [17]-[20], an extensive list of safety applications has been formulated and shown in Table I. Message delivery and reliability is a major concern in vehicular networks, due to which a differentiated QoS mechanism is proposed. This mechanism works on the principle of indexing various applications according to their requirements, motivated from QoS class identifier (QCI) implemented in LTE networks [21]. In Table I, each application is categorized and assigned an SAI. This SAI, which is a number ranging between $1-9$, is included in the transmitted packet appended before the IP header by the application layer as shown in Fig. 1. The categorization and assignment of SAI for our model is further discussed in Section III.

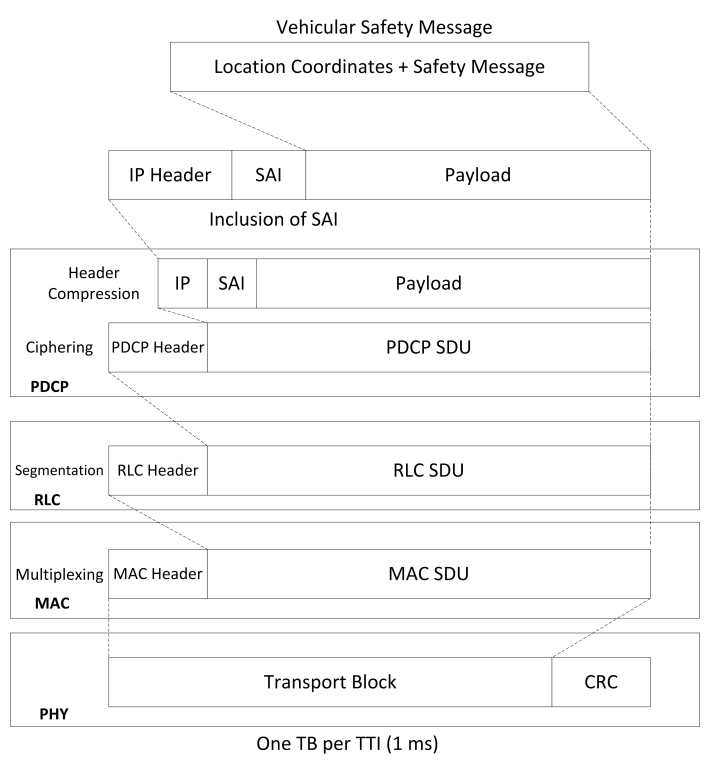

Fig. 1. SAI Inclusion in LTE Message Structure

This concept is implemented in the form of an algorithm proposed in the following subsection.

\section{A. SAI Algorithm}

With the concept of safety application indexing, we propose an algorithm that does not include the use of group formation or IEEE $802.11 \mathrm{p}$. The proposed algorithm is a process that is carried out on the VSA server located in the LTE CN. When the vehicles start transmissions, the packet is carried from the eNodeB to the VSA server via the $\mathrm{CN}$. This packet contains vehicles' location and corresponding payload. As soon as the server starts receiving these messages, it locates all the vehicles being served by the network, forming a virtual geographical map of the served area. The VSA server, while receiving the packets, will also extract the SAI information from the received packet. This SAI information will then be checked against the database stored in the server (Table I). With this SAI, the server retrieves the transmission beacon frequency $B F_{i}$ and awareness range $R_{i}$ requirement of the

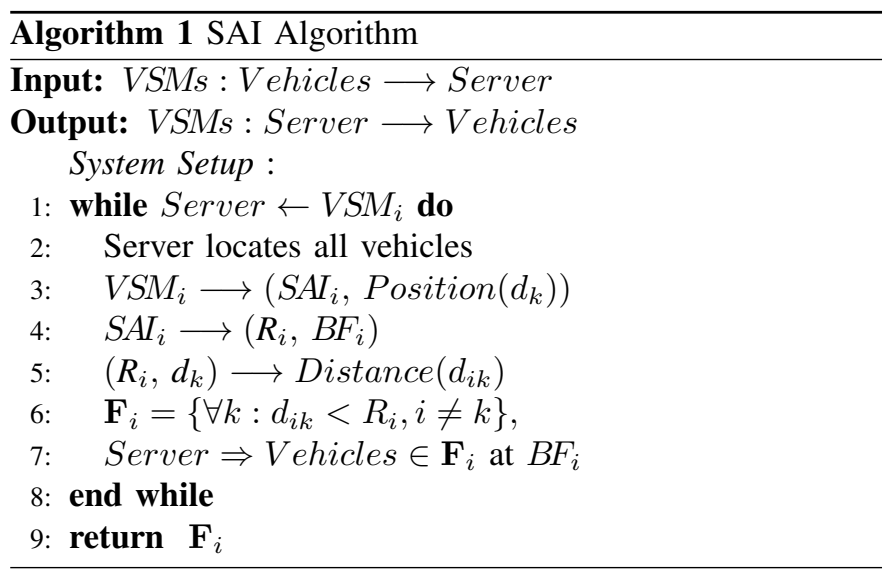


TABLE I

SAFETY APPLICATION REQUIREMENTS \& SAIS

\begin{tabular}{|c|c|c|c|c|c|c|}
\hline Safety Application & $\begin{array}{l}\text { Message } \\
\text { Type }\end{array}$ & Transmitted Data & $\begin{array}{l}\text { Critical } \\
\text { Latency }\end{array}$ & $\begin{array}{l}\text { Transmission } \\
\text { Frequency }\end{array}$ & $\begin{array}{l}\text { Transmission } \\
\text { Range }\end{array}$ & SAI \\
\hline Intersection Collision Warning & CAM & $\begin{array}{l}\text { Vehicle type, position, heading, ve- } \\
\text { locity, acceleration, yaw rate }\end{array}$ & $\sim 100 \mathrm{~ms}$ & $10 \mathrm{~Hz}$ & $150 \mathrm{~m}$ & \multirow{3}{*}{1} \\
\hline Lane Change Assistance & CAM & $\begin{array}{l}\text { Position, heading, velocity, acceler- } \\
\text { ation, turn signal status }\end{array}$ & $\sim 100 \mathrm{~ms}$ & $10 \mathrm{~Hz}$ & $150 \mathrm{~m}$ & \\
\hline $\begin{array}{lll}\text { Cooperative } & \text { Forward } & \text { Collision } \\
\text { Warning } & & \end{array}$ & CAM & $\begin{array}{l}\text { Vehicle type, position, heading, ve- } \\
\text { locity, acceleration, yaw rate }\end{array}$ & $\sim 100 \mathrm{~ms}$ & $10 \mathrm{~Hz}$ & $150 \mathrm{~m}$ & \\
\hline Slow Vehicle Indication & $\begin{array}{l}\text { CAM / } \\
\text { DENM }\end{array}$ & $\begin{array}{l}\text { Vehicle type, position, heading, ac- } \\
\text { celeration, velocity }\end{array}$ & $\sim 100 \mathrm{~ms}$ & $2 \mathrm{~Hz}$ & $200 \mathrm{~m}$ & 2 \\
\hline $\begin{array}{l}\text { Traffic Light Speed Advisory/ Vio- } \\
\text { lation }\end{array}$ & $\begin{array}{l}\text { CAM / } \\
\text { DENM }\end{array}$ & $\begin{array}{l}\text { Signal phase, timing, position, di- } \\
\text { rection, road geometry }\end{array}$ & $\sim 100 \mathrm{~ms}$ & $2 \mathrm{~Hz}$ & $150 \mathrm{~m}$ & \multirow[t]{2}{*}{3} \\
\hline $\begin{array}{l}\text { Motorcycle Approaching Indica- } \\
\text { tion }\end{array}$ & CAM & $\begin{array}{l}\text { Vehicle type, position, heading, ve- } \\
\text { locity }\end{array}$ & $\sim 100 \mathrm{~ms}$ & $2 \mathrm{~Hz}$ & $150 \mathrm{~m}$ & \\
\hline Overtaking Vehicle Warning & CAM & $\begin{array}{l}\text { Position, velocity, yaw rate, accel- } \\
\text { eration }\end{array}$ & $\sim 100 \mathrm{~ms}$ & $10 \mathrm{~Hz}$ & $300 \mathrm{~m}$ & 4 \\
\hline Head on Collision Warning & CAM & $\begin{array}{l}\text { Vehicle type, position, heading, ve- } \\
\text { locity, acceleration, yaw rate }\end{array}$ & $\sim 100 \mathrm{~ms}$ & $10 \mathrm{~Hz}$ & $200 \mathrm{~m}$ & 5 \\
\hline Collision Risk Warning & $\begin{array}{l}\text { CAM / } \\
\text { DENM }\end{array}$ & $\begin{array}{l}\text { Vehicle type, position, heading, ve- } \\
\text { locity, acceleration, yaw rate }\end{array}$ & $\sim 100 \mathrm{~ms}$ & $10 \mathrm{~Hz}$ & $300-500 \mathrm{~m}$ & 6 \\
\hline Emergency Vehicle Warning & $\begin{array}{l}\text { CAM / } \\
\text { DENM }\end{array}$ & $\begin{array}{l}\text { Position, heading, velocity, acceler- } \\
\text { ation }\end{array}$ & $\sim 100 \mathrm{~ms}$ & $2 \mathrm{~Hz}$ & $300 \mathrm{~m}$ & 7 \\
\hline Cooperative Merging Assistance & CAM & $\begin{array}{l}\text { Curve location, curvature, slope, } \\
\text { speed limit, surface }\end{array}$ & $\sim 1000 \mathrm{~ms}$ & $1 \mathrm{~Hz}$ & $250 \mathrm{~m}$ & 8 \\
\hline Speed Limits Notification & CAM & $\begin{array}{l}\text { Velocity, acceleration, position, } \\
\text { speed limit, heading }\end{array}$ & $\sim 100 \mathrm{~ms}$ & $1-10 \mathrm{~Hz}$ & $300 \mathrm{~m}$ & 9 \\
\hline
\end{tabular}

application that vehicle $i$ is utilizing. Using the required awareness range, the server determines the forwarding set of vehicles (neighboring vehicles) by:

$$
\mathbf{F}_{i}=\left\{\forall k: d_{i k}<R_{i}, i \neq k\right\},
$$

where $d_{i k}$ is the distance from vehicle $i$ to the neighboring vehicle $k$. Recalling the concept of data freshness, the VSA server will discard the packet if it arrives later than the beacon inter arrival time $\left(1 / B F_{i}\right)$.

\section{B. Dynamic Adaptive Awareness Range}

In our previous work [14], we proposed adaptive awareness range for VANETs over LTE networks. It was observed that with range up to $500 \mathrm{~m}$ for $2 \mathrm{~Hz}, 250 \mathrm{~m}$ for $4 \mathrm{~Hz}$ and $10 \mathrm{~Hz}$

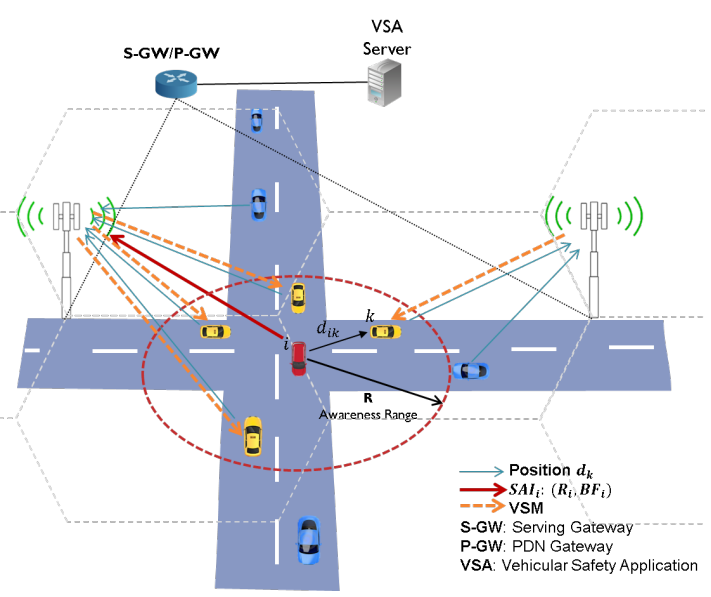

Fig. 2. SAI Awareness Range beacon frequency, the system satisfied the requirements. This proved that the awareness range can be dynamically adapted to the application requirement and traffic conditions, saving the processing time of transmission range on the vehicle. Using the SAI algorithm, VSA server can dynamically adapt awareness range and forward the packets accordingly as shown in Fig. 2.

\section{SySTEM MODEL}

The network consists of $N$ vehicles uniquely identified by their number $i,(i=1 \ldots N)$. Vehicles are assumed to use FDD LTE transceivers with $2 \times 10 \mathrm{MHz}$ bandwidth, uplink carrier frequency $1715 \mathrm{MHz}$ and downlink carrier frequency $2115 \mathrm{MHz}$ (band 4) [21, Table 5.5-1]. We refer to vehicles as LTE user equipments (UEs). These UEs are assumed to be moving in a Manhattan grid model created using BonnMotion [22]. Fig. 3 illustrates the service area modeled in ns-3 [23], composed of $5 \times 5$ blocks of $400 \mathrm{~m}$ each with two way roads. Vehicles move at an average speed matched to the 3GPP extended vehicular A (EVA) model radio environment designed using MATLAB [24]. Simulation parameters used are given in Table II.

Furthermore, we assume that the safety application sends periodic UDP packets to the SAI server (uplink). The eNodeBs (eNBs) are connected to the mobility management entity (MME) through their S1-AP interface and to the serving gateway (S-GW) and packet data network gateway (P-GW) through their S1-U interfaces. Interconnection from the P-GW to the VSA server is modeled using an error free $10 \mathrm{Gbps}$ point-to-point link and TCP/IP version 4 . The packet payload is assumed to be 256 bytes including user's location, SAI and the safety message. 
The LTE functionality is implemented through the LTE EPC Network SimulAtor (LENA) module that includes highly detailed eNB and UE functionalities following 3GPP standards. To manage handover and Internet connections, eNBs are interconnected through their X2 interfaces and connected to the evolved packet core (EPC). Positioning of the server will have a significant impact on the vehicular network performance. Kato et al. [9] analytically evidenced that if the server is placed close to the eNodeB or even at the EPC, it will have a considerable influence on the practical feasibility of the system. For our simulation model, we assume the VSA server is positioned in the EPC, keeping the link between PGW and VSA server an error free $10 \mathrm{Gbps}$ point-to-point link.

Archer in [25] carried out a survey on traffic safety problems in urban areas. It was concluded that overtaking tends to occur less frequently within urban areas where the speed limit is less than $50 \mathrm{~km} / \mathrm{h}$. Lane changing on the other hand occurs quite frequently within urban areas however due to low speed limits, does not tend to pose any serious traffic safety problems. The number of rear-end accidents is greater within urban areas than in rural areas and similarly, due to higher level of congestion and higher number of traffic junctions, there is a greater number of opportunities for turning and crossing accidents within urban area. According to another survey of 4500 crashes by the Insurance Institute of Highway Safety [26], $13 \%$ of accidents are during lane change maneuvers, $12 \%$ are intersection collisions, $22 \%$ are due to traffic light violation, $9 \%$ are head on collisions, $18 \%$ include left turning crashes, $12 \%$ are due to emergency vehicles parked on blind turns and $14 \%$ are due to over speeding. In the light of these statistics, for our urban environment, the SAIs we utilize in

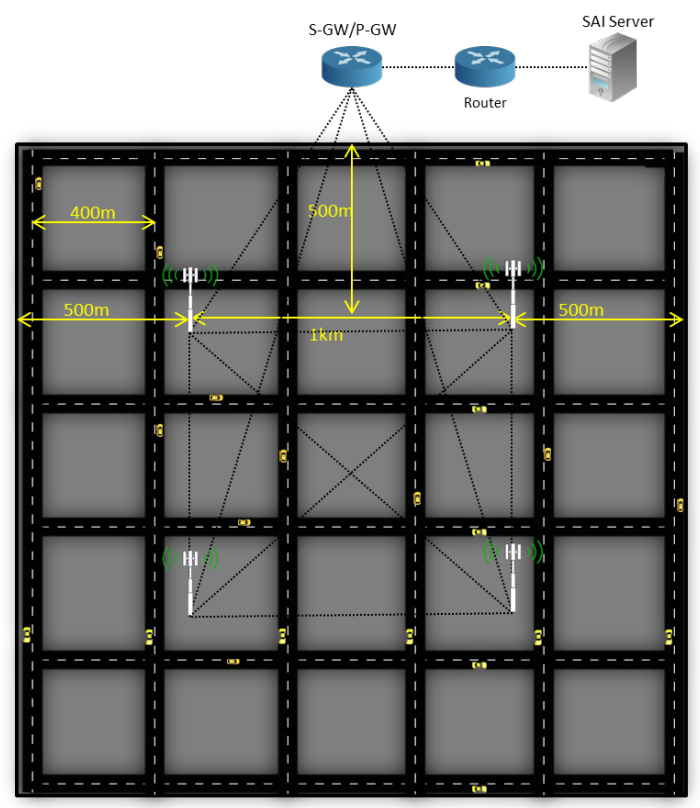

Fig. 3. Manhattan grid model covered by 4 sites with $1000 \mathrm{~m}$ intersite distance and 3 cells/site.
TABLE II

LTE Simulation PARAMETERS

\begin{tabular}{l|l} 
Parameter & Value \\
\hline \hline Simulation time & 100 seconds. \\
Road model & Manhattan grid model (two ways roads) \\
LTE network & 4 sites with 3 cells/site, $1000 \mathrm{~m}$ ISD. \\
Transmission power & eNB: $40 \mathrm{dBm}, \mathrm{UE}: 23 \mathrm{dBm}$. \\
Carrier frequency DL/UL & $2115 \mathrm{MHz} / 1715 \mathrm{MHz}$. \\
Channel bandwidth & $2 \times 10 \mathrm{MHz}(2 \times 50 \mathrm{RBs})$ \\
Noise Figure & eNB: $5 \mathrm{~dB}, \mathrm{UE}: 9 \mathrm{~dB}$. \\
UE antenna model & Isotropic $(0 \mathrm{dBi})$. \\
eNB antenna model & $15 \mathrm{~dB}$ Cosine model, $65^{\circ} \mathrm{HPBW}$. \\
Scheduling algorithm & Proportional Fair. \\
Handover algorithm & A2A4RSRQ, RSRQ threshold $-5 \mathrm{~dB}$, \\
& and NeighbourCellOffset=2 $(1 \mathrm{~dB})$. \\
Frequency reuse & Distributed Fractional Freq. Reuse. \\
Path loss model & LogDistance $(\alpha=3)$ and \\
& $3 \mathrm{GPP}$ Extended Vehicular A model. \\
Safety message format & $256 \mathrm{bytes}$ UDP. \\
Number of vehicles & $100,150,200$. \\
Average vehicle's speed & $40 \mathrm{~km} / \mathrm{h}-60 \mathrm{~km} / \mathrm{h}$. \\
\hline
\end{tabular}

our simulations are $1(25 \%), 3(22 \%), 5(9 \%), 6(18 \%), 7$ $(12 \%)$ and $9(14 \%)$.

\section{A. Performance Measures}

We compare our results with the network which does not implement the SAI algorithm. The primary performance measures used are the end-to-end delay, the downlink goodput and the number of downlink flows. In addition, we use the notation $\overline{\left|\mathbf{F}_{i}\right|}$ to represent the average number of neighbors, calculated over all broadcasted beacons. The end-to-end delay of a beacon $\left(D_{i k}\right)$ is defined as the time measured from the start of its transmission at vehicle $i$ 's application layer until its successful reception at vehicle $k$ 's application layer. Furthermore, the goodput is defined as the number of information bits received at the application layer per unit of time.

\section{Simulation Results}

Reliability and robustness of vehicular networks are function of the requirements set by the standards. In order to achieve an acceptable vehicular network, parameters such as delay and packet delivery are to be satisfied. As mentioned earlier, LTE systems do not cater high beacon frequencies and larger awareness ranges to meet these stringent requirements. Moreover, there is still a need to make the system more robust and efficient by utilizing the resources intelligently. In a capacity limited cellular network, congestion and waste of resources can lead to a network that does not accommodate VANETs effectively. Therefore, we test 100 and 150 vehicles in an area of $2 \mathrm{~km}$ by $2 \mathrm{~km}$ with 4 eNBs having 3 sectors per site as shown in Fig. 3.

We first validate our proposed system by comparing our achieved end-to-end delay with a scenario that does not employ SAI algorithm. Fig. 4 shows the cumulative distribution function (CDF) of the end-to-end delay for 100 and 150 vehicles at an average speed of $60 \mathrm{~km} / \mathrm{h}$ with and without the implementation of SAI algorithm. The scenario being compared has the awareness range set to $500 \mathrm{~m}$ and beacon 


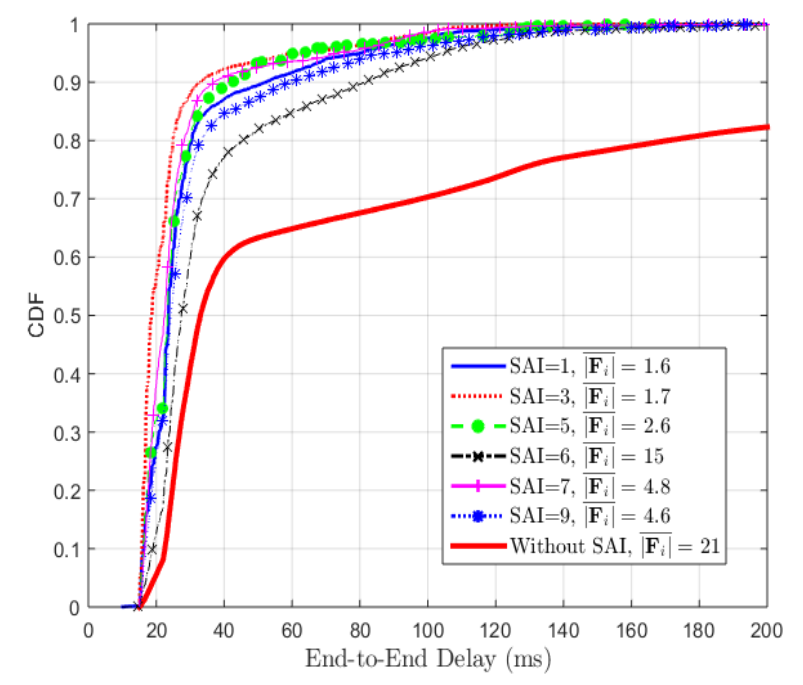

(a)

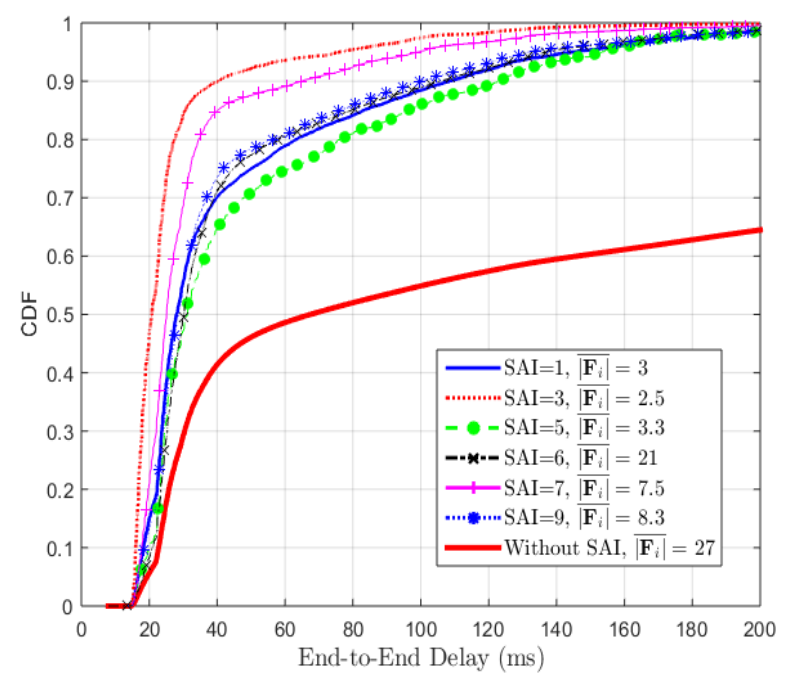

(b)

Fig. 4. LTE end-to-end delay at average speed $60 \mathrm{~km} / \mathrm{h}$ (4 sites, 3 sectors/site) and (a) 100 vehicles, (b) 150 vehicles.

frequency to $10 \mathrm{~Hz}$. We observe a significant decrease in the end-to-end delay post SAI algorithm implementation. Probability for the end-to-end delay to be less than $100 \mathrm{~ms}$ is above $80 \%$ in both scenarios whereas without the algorithm, this probability is below $70 \%$ for 100 vehicles (Fig. 4(a)) and below $60 \%$ for 150 vehicles (Fig. 4(b)). The variation in this delay between various SAIs is because of the difference in transmission parameters. Larger awareness range leading to higher number of neighbors $\overline{\left|\mathbf{F}_{i}\right|}$ and higher beacon frequency results in more congestion and large queuing times. The reason for better delay values for SAI algorithm is mainly the result from complying with the required transmission parameters as mentioned in Table I. This probability of successful packet arrival within the required latency is not specified in the standards. However for VANETs, it is generally low ranging between $60 \%$ to $80 \%$ [27]. Comparing with the scenarios without SAI implementation, the effect of multipath EVA fading

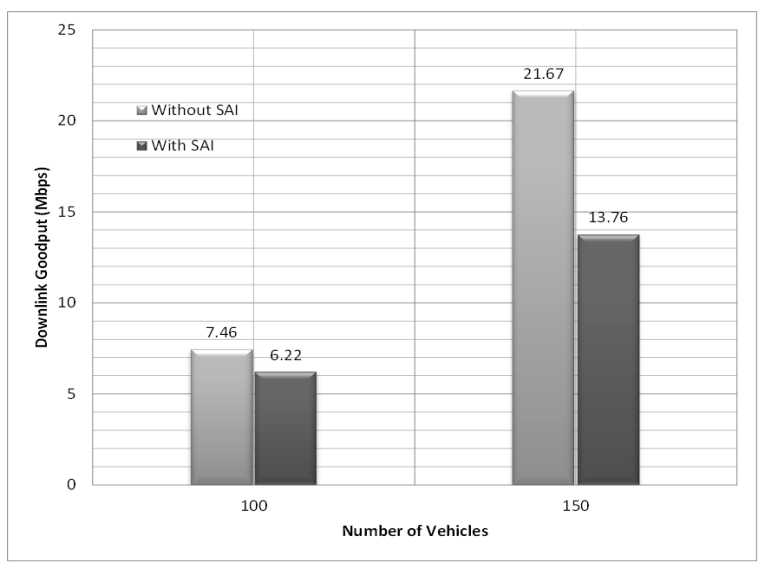

Fig. 5. Downlink goodput for 100 and 150 vehicles at an average speed $60 \mathrm{~km} / \mathrm{h}$ (4 sites and 3 sectors $/$ site). model can be observed, since the average delay value with LTE systems was found to be above $80 \mathrm{~ms}$ for 100 vehicles and above $100 \mathrm{~ms}$ for 150 vehicles in [11]. Nonetheless, it can be concluded that with the implementation of SAI algorithm, the probability of end-to-end delay less than $100 \mathrm{~ms}$ is above $90 \%$ for 100 vehicles and above $85 \%$ for 150 vehicles as shown in Fig. 4(a) and 4(b) respectively.

Fig. 5 shows the aggregate downlink goodput for the same scenario investigated for end-to-end delay. After the implementation of SAI algorithm, the downlink goodput for 100 vehicles dropped from $7.46 \mathrm{Mbps}$ to $6.22 \mathrm{Mbps}$ and for 150 vehicles it dropped from $21.67 \mathrm{Mbps}$ to $13.76 \mathrm{Mbps}$. This significant decrease in the downlink direction is again due to the restriction of unnecessary data dissemination from the VSA server to vehicles. Eventually, this decrease of goodput results in lower traffic and ultimately less load on the LTE system. The increase in the downlink goodput for the scenario without SAI, explains the high end-to-end delay observed in Fig. 4, showing a burst of packet in the downlink leading to waiting time in the queue.

Cellular networks have a number of applications running simultaneously. Users are trying to access and reserve resources at various times. Running vehicular communications with these capacity limited networks can degrade the QoS of the system leading to unacceptable performance. As mentioned in Section I, number of previous works have contributed in reducing the downlink traffic for vehicular networks in order to utilize the resources more efficiently. In order to test our system's efficiency, we investigate the number of downlink flows generated from the VSA server to the vehicles via EPC and eNBs over a period of $100 \mathrm{~s}$ in Fig. 6. We observe that there is a significant decrease in the number of flows in the downlink direction. Urban scenario that does not employ SAI, is transmitting packets at a beacon frequency of $10 \mathrm{~Hz}$ in an 
awareness range of $500 \mathrm{~m}$. For the scenarios shown on the $\mathrm{x}$ axis of Fig. 6, the number of flows decreases by 63\%, 64\%, $58 \%$ and $60 \%$ respectively. This low number of flows is due to the system adapting to various vehicular applications utilizing the required transmission parameters using our proposed SAI algorithm.

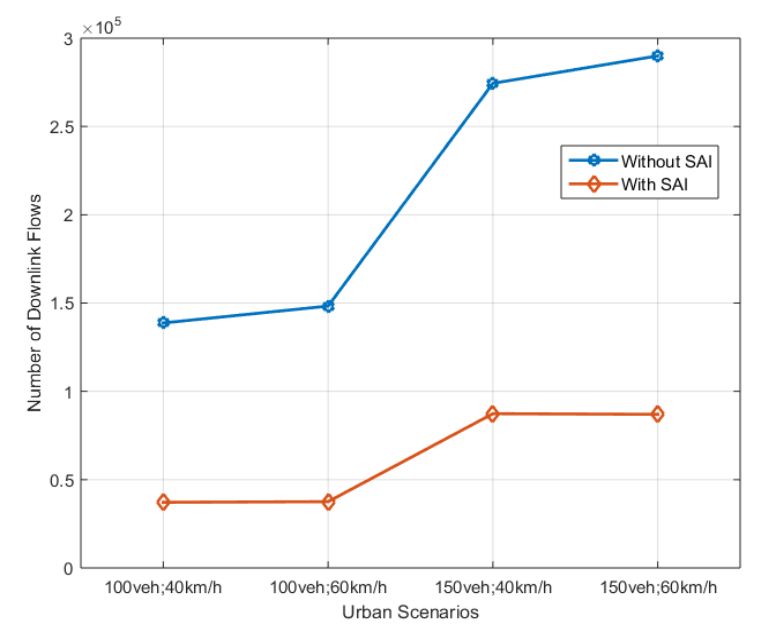

Fig. 6. Number of downlink flows for 100 and 150 vehicles at an average speed of $40 \mathrm{~km} / \mathrm{h}$ and $60 \mathrm{~km} / \mathrm{h}$ (4 sites and 3 sectors/site).

\section{CONCLUSiOn AND Future Work}

This paper proposes the safety application identifier concept and an algorithm that dynamically adapts to vehicular safety application transmission requirements at the VSA server within the EPC. LTE vehicular networks where MBMS functionality, D2D, and clustering are not available, our algorithm proves to be promising in obtaining better performance. Simulations are carried out in a multicell vehicular urban radio environment employing multipath fading models. Results obtained from our simulations show that dynamic adaptation of transmission parameters for various safety applications can significantly improve the operation of the system. After implementing the proposed algorithm, probability of experiencing an end-to-end delay of less than $100 \mathrm{~ms}$ increases by around $20 \%$, downlink goodput decreases significantly from $21.67 \mathrm{Mbps}$ to $13.76 \mathrm{Mbps}$ for 150 vehicles, and the number of downlink flows decreases by about $60 \%$. Hence, it can be concluded that by dynamic adaptation, even in a harsh environment employing multipath fading, load on the system caused by vehicular application can be decreased by reducing the traffic load on the cellular network. In the future, we plan to expand our algorithm to various other aspects of vehicular networks like traffic efficiency and infotainment focusing on PHY layers, with the inclusion of background traffic. Further work will also explore the possibility of including this SAI in the MAC PDU control elements instead of the application layer, bringing the processing to the user edge of the network.

\section{REFERENCES}

[1] S. Al-Sultan, M. M. Al-Doori, A. H. Al-Bayatti, and H. Zedan, "A comprehensive survey on vehicular ad hoc network," Journal of network and computer applications, vol. 37, pp. 380-392, 2014.
[2] K. Tanuja, T. Sushma, M. Bharathi, and K. Arun, "A survey on VANET technologies," International Journal of Computer Applications, vol. 121, no. $18,2015$.

[3] G. Remy, S.-M. Senouci, F. Jan, and Y. Gourhant, "LTE4v2x: LTE for a Centralized VANET Organization," in IEEE Global Telecommunications Conference. Houston, TX, USA: IEEE, Dec. 2011, pp. 1-6.

[4] Y. Yang, P. Wang, C. Wang, and F. Liu, "An eMBMS based congestion control scheme in cellular-VANET heterogeneous networks," in 17th International IEEE Conference on Intelligent Transportation Systems (ITSC), Oct. 2014, pp. 1-5.

[5] S. Taha and X. Shen, "A physical-layer location privacy-preserving scheme for mobile public hotspots in nemo-based vanets," IEEE Transactions on Intelligent Transportation Systems, vol. 14, no. 4, pp. 16651680, Dec 2013.

[6] Public warning system (PWS) requirements (release 13), 3GPP TS 22.268 V13.0.0, Dec. 2015.

[7] Overall description; Stage 2 (Release 13), 3GPP TS 36.300 V13.2.0, Dec. 2015

[8] H. Hartenstein and K. Laberteaux, "VANET vehicular applications and inter-networking technologies," 2009.

[9] S. Kato, M. Hiltunen, K. Joshi, and R. Schlichting, "Enabling vehicular safety applications over lte networks," in International Conference on Connected Vehicles and Expo (ICCVE), Dec 2013, pp. 747-752.

[10] A. Moller, J. Nuckelt, D. M. Rose, and T. Kurner, "Physical Layer Performance Comparison of LTE and IEEE $802.11 \mathrm{p}$ for Vehicular Communication in an Urban NLOS Scenario," in IEEE 80th Vehicular Technology Conference (VTC2014-Fall), Sep. 2014, pp. 1-5.

[11] Z.H. Mir, and F. Filali, "LTE and IEEE 802.11p for vehicular networking: a performance evaluation," EURASIP Journal on Wireless Communications and Networking, no. 1, pp. 1-15, 2014.

[12] A. Vinel, "3GPP LTE versus IEEE 802.11p/WAVE: which technology is able to support cooperative vehicular safety applications?" Wireless Communications Letters, IEEE, vol. 1, no. 2, pp. 125-128, 2012.

[13] S. Sesia, I. Toufik, and M. Baker, LTE, the UMTS long term evolution: from theory to practice. Wiley Publishing, 2009.

[14] M. S. Garache, S. Ansari, T. Boutaleb, C. Gamio, S. Sinanovic, and I. Krikidis, "Adaptive awareness range for vehicular safety message applications over lte networks," 2016, to be published.

[15] G. Araniti, C. Campolo, M. Condoluci, A. Iera, and A. Molinaro, "LTE for vehicular networking: a survey," Communications Magazine, IEEE, vol. 51, no. 5, pp. 148-157, 2013.

[16] Intelligent transport systems (ITS); basic set of applications; Part2: specification of cooperative awareness basic service, ETSI TS 102 637-2 V1.2.1, Mar. 2011.

[17] "Vehicle safety communications project task 3 final report," US Department of Transportation, Tech. Rep., 2005.

[18] Intelligent transport systems (ITS); basic set of applications; part3: specifications of decentralized environmental notification basic service, ETSI TS 102 637-3 V1.1.1, Sep. 2010.

[19] C.L. Robinson, D. Caveney, L. Caminiti, G. Baliga, K. Laberteaux and P. R. Kumar, "Efficient message composition and coding for cooperative vehicular safety applications," IEEE Transactions on Vehicular Technology, vol. 56, no. 6, pp. 3244-3255, 2007.

[20] Derek Caveney, "Cooperative vehicular safety applications," IEEE Control Systems, vol. 30, no. 4, pp. 38-53, 2010.

[21] E-UTRA Base Station (BS) radio transmission and reception (Release 12), 3GPP TS 36.104 V12.10.0, Jan. 2016.

[22] BonnMotion: A Mobility Scenario Generation and Analysis Tool, University of Osnabrück, Nov. 2015. [Online]. Available: https://sys.cs.uos.de/bonnmotion/doc/README.pdf

[23] Model library release $n s-3.2$, Ns-3 network simulator, 2015. [Online]. Available: https://www.nsnam.org/docs/models/html/lte-design.html

[24] G. T. . V8.2.0, Evolved Universal Terrestrial Radio Access (E-UTRA), Base Station (BS) radio transmission and reception (Release 8). 3GPP, May 2008.

[25] J. Archer and K. Vogel, "The traffic safety problem in urban areas," 2000.

[26] "Urban crashes," Insurance Institute for Highway Safety, Tech. Rep., 1999.

[27] W. Sun, T. Fu, Y. Su, F. Xia, and J. Ma, "ODAM-C: an improved algorithm for vehicle ad hoc network," in International Conference on Internet of Things, and 4th International Conference on Cyber, Physical and Social Computing (iThings/CPSCom), Oct 2011, pp. 152-156. 